\title{
Analysis of Allergy Symptoms and Quality of Life among University Students with Allergic Rhinitis
}

\author{
Mi Ryeong Song ${ }^{1}$, Joon Soo Park ${ }^{2}$ \\ ${ }^{1}$ Department of Nursing, Hoseo University, Asan; '2Department of Medicine, Soonchunhyang University, Asan, Korea
}

\begin{abstract}
Purpose: The purpose of this study was to analyze the symptoms of allergic rhinitis among university students and assess their quality of life (QOL) in order to establish an effective program for university students with allergic rhinitis. Methods: The data were collected in May, 2012 in a university school health center. The collected data were analyzed in terms of frequency, percentage and mean for the symptom types and QOL among 131 university students with allergic rhinitis. An independent $\mathrm{t}$-test was conducted to determine differences in QOL according to general and disease related characteristics. Results: Symptoms were reported in the following order: nasal obstruction, rhinorrhea, sneezing, and nasal itching respectively. The mean score of QOL of the participants was 2.24 (5 point). Nasal symptoms such as rhinorrhea $(M=3.16)$ and nasal obstruction $(M=3.12)$ had the highest score and affected $Q O L$ badly in the item analysis. QOL differed according to the diagnosis of allergic rhinitis history, skin test reaction, some symptoms and allergens. Conclusion: To establish an effective management program for increasing QOL among university students with allergic rhinitis, symptom management methods for nasal obstruction and rhinorrhea should be included in the program.
\end{abstract}

Key Words: Rhinitis; Quality of life; Students; Allergens

국문주요어: 알레르기성 비염, 삶의 질, 학생, 알레르기원

\section{INTRODUCTION}

As the importance of the environment on all aspects of human life has increased, environmental health issues have become much more prominent in the 21st century (Jegatheesan \& Shu, 2009). As the environment becomes more problematic and contaminated and the number of people suffering from diseases brought on by environmental influences increases, the necessity of implementing nursing strategies for people with environment related health problems has also increased. In particular, there has been a rapid increase in the prevalence of allergic diseases that is associated with a decline in air quality and changes in weather patterns and the increase in Western style housing and eating habits in Korea (Son et al., 2007). In fact, the increase in allergies is tak- ing place across the world (Baiardini et al., 2008). 20\% of the world's population has experienced some kind of allergy (World Health Organization, 2002).

Allergies are the first self-reported health problems students experienced in school years (The American College Health Association, 2008). Allergic diseases include allergic rhinitis, atopic dermatitis, asthma and allergic conjunctivitis etc, and among these, allergic rhinitis represents a global health problem affecting $10 \%$ to $20 \%$ of the population (Brozek et al., 2010). And it is especially prevalent among people in their twenties, according to a national nutritional and health survey in Korea (Ministry of Health and Welfare, 2009).

The health status of people in their twenties has a particular significance for our society as they begin to enter adult society, become the

Corresponding author: Mi Ryeong Song

Department of Nursing, Hoseo University, 20 Hoseo-ro 79beon-gil, Asan 336-795, Korea

Tel:+82-41-540-9531Ｆax:+82-41-540-9558Ｅ-mail:songmr@hoseo.edu

*This research was supported by Basic Science Research Program through the National Research Foundation of Korea (NRF) funded by the Ministry of Education, Science and Technology (2012014240).

투고일: 2013년 9월 22일 심사의뢰일: 2013년 9월 26일 게재확정일: 2013년 11월 7일

This is an Open Access article distributed under the terms of the Creative Commons Attribution Non-Commercial License(http://creativecommons.org/licenses/by-nc/3.0) which permits unrestricted non-commercial use, distribution, and reproduction in any medium, provided the original work is properly cited. 
major economic productive age group, and start to settle down and rear children. Furthermore, as the incidence of allergic rhinitis has increased, the burden of medical costs has also increased (Dalal, Stanford, Henry, \& Borah, 2008; Demoly, Allaert, \& Lecasble, 2002) and this has put a tremendous strain on health care finances. Allergies are beginning to have a socio-economic impact on society through rising medical costs and the number of days lost at school and work.

Allergic rhinitis is a serious complaint that induces discomfort and seriously impacts the quality of life (QOL) of an individual. Sleep deprivation and fatigue caused by the symptoms of allergic rhinitis, such as itching and obstruction of nose, leads to lethargy and impaired concentration (Song \& Suh, 2010). This limits the ability of a person to fully engage in activities and can negatively affect the potential for personal achievement as well as negatively impacting on emotions and general personality. Furthermore, allergic rhinitis causes stress and financial hardship to the family of those suffering from this complaint. Finally, allergic rhinitis can adversely impact on a patient's work, school performance, and QOL (Greiner, Hellings, Rotiroti, \& Scadding, 2011; Holmes \& Scullion, 2012).

Accordingly, proper intervention programs to combat allergy rhinitis and alleviate the distress of sufferers are needed. Allergic rhinitis is difficult to completely cure and self-care is needed to control symptoms. It is important to bring relief to those suffering from allergic symptoms (O'Connor et al., 2008). Allergic symptoms can be alleviated effectively via behavioral changes in daily life. Practical strategies to promote behavioral changes should be needed for the effective management of allergies. According to a survey carried out on peoples' awareness of the influence of the environment on health in Korea, most people recognize that behavioral practices in daily life are very important to prevent and manage environmental diseases (Ministry of Environment, 2008). This supports the need for a program to prevent and manage allergies that includes strategies to modify behavioral practices in daily life.

As allergic rhinitis is believed to have many causal factors, so various factors should be considered when developing a program to prevent and manage allergic rhinitis. Allergic rhinitis has various symptoms, it has physical symptoms such as sneezing, rhinorrhea, nasal obstruction, nasal itching and headaches (Demoly et al., 2001; Greiner et al., 2011), and also has psychosocial manifestations such as stress, sleep deprivation and dysfunction (Demoly, Jankowski, Chassany, Bessah, \& Allaert, 2011; Song \& Suh, 2010; Thompson, Juniper, \& Meltzer, 2000). The factors that induce this allergy and the methods for alleviating it differ from patient to patient. Therefore, an approach based on an analysis of a patient' s physical state and situation is desirable to devise a comprehensive program for the prevention and management of allergic symptoms through behavioral practices in daily life.

Allergies are related to individuals' physical, chemical, psychosocial status and should be treated via a complete assessment and analysis of these factors. However, previous studies were chiefly conducted with a focus on the prevalence of allergies so there is a lack of information as to how to establish an effective program for the patients with allergic rhinitis.

Finally, there is a need to analyze symptoms and assess allergic rhinitis related QOL in order to understand allergic rhinitis properly and to establish an effective management program for university students with allergic rhinitis. The results of this study could serve to enhance QOL of university students with allergic rhinitis.

The purpose of this study was to identify symptoms and assess QOL among university students with allergic rhinitis. The specific goals of this study were as follows.

1) To analyze allergic rhinitis symptoms and the type of allergens.

2) To assess the QOL of university students with allergic rhinitis.

3) To analyze differences in QOL of university students with allergic rhinitis according to general and disease related characteristics.

\section{METHODS}

\section{Study design}

This study used an explorative cross-sectional design to analyze symptoms and assess QOL among university students with allergy rhinitis in Korea.

\section{Setting and samples}

The data were collected in May, 2012 in a university school health center. Students who expressed a willingness to participate in the research study were provided with a description of the purpose and method of this study, and then they signed a consent agreement to participate. A power analysis indicated explanatory powers of over $80 \%$ in a total sample size of 131 with the medium effect size $(\mathrm{d}=0.5)$ at alpha $=.05$ (Fall, Erdfelder, Buchner, \& Lang, 2009).

The inclusion criteria were as follows.

- Those who had allergic rhinitis symptoms. 
- Those who were university students.

- Those who were in their twenties and had no medical diagnoses.

- Those who had no other chronic illness except allergic rhinitis.

- Those who took no allergy medication (Anti-Histamine).

\section{Ethical considerations}

This study was approved by the Institutional Review Board of H University (No 20120004). The subjects participated in this study voluntarily after hearing an explanation about the purposes and the processes of the study. The subjects were informed that they had the right to refuse to participate, that they could stop participating at anytime during the study, that their confidentiality would be respected, and that they could expect some reward for participating in the study. The subjects then signed an agreement consenting to participate in the study. And then the study proceeded on the basis of the consent given and with the dignity of the participants respected at all times. For the safety of the students, a medical doctor was present at all the times and assessed the students during the process of skin prick test.

\section{Measurements}

\section{1) General and disease related characteristics}

The variables for general and disease related characteristics employed in this study included: Gender; Any history in the family of allergic disease; Whether the sufferer had ever been diagnosed or treated for allergy rhinitis (Have you ever been diagnosed with allergic rhinitis? Have you ever been treated for allergic rhinitis?); Symptom experiences (What type of symptom do you experienced?); Occurrence month (When do you have the allergy symptom?); Perceived reason for the occurrence (When do you perceive the allergy symptom occurring?), Management method (What do you do to manage your allergic symptoms?). Symptom experiences, occurrence month, perceived reason for the occurrence and management method were permitted multiple choices.

\section{2) $\mathrm{QOL}$}

Five point Likert-type scale for perennial allergic rhinitis patients developed by Park et al. (2002) was used. This scale included a total of 28 items. The scale included 7 subcategories such as 'practical problems in daily life', 'sleep disturbances', 'nasal symptoms', 'general symptoms', 'limitations on activities', 'emotional problems', 'ocular symptoms', and each subcategory contained 3-6 items. The higher the score, the lower the allergic rhinitis related QOL among patients with allergic rhinitis. The Chronbach's alpha was 91 in the study by Park et al. (2002). It was .89 in this study.

\section{3) Skin prick test}

This test is a kind of allergy skin test to detect allergens in patients reporting allergic symptoms. The allergen solution is dripped onto the inside of the lower arm and then gently pricked on to the skin surface with a lancet. 8 allergen solutions (D. Farinae, D. pteronyssinus, Cat hair, Dog hair, Cockroach, Ragweed, Mugwort, Dirch-Alder Mix: produced by Lofarma company in Italy) which are reported as common allergens of allergic rhinitis in Korean were used, and normal saline and a histamine were used as a control in this test. The response was evaluated by examining the prick site for wheal and erythema after 15 minutes (Greiner et al., 2011). The response was evaluated as a positive reaction to each allergen when the wheal and erythema were the same or bigger than the histamine induced wheal and erythema (Son et al., 2007). Wheal is a hard and elevated mass that develops on the skin after an allergic reaction and erythema refers to the redness of the skin around the wheal. The diameter of the wheal was measured with a ruler. The longest diameter of the wheal area was measured in addition to the line running perpendicular to the longest diameter and these numbers were added together and divided by two. The wheal was considered more important than the erythema in the evaluation process. The wheal was given priority and was given more attention during the evaluation process. The skin prick test was done by a registered nurse who had more than 10 years experience working in a clinic dealing with allergies within a university hospital.

\section{Data collection procedure}

The process of the data collection was as follows.

- This study was announced by putting posters up around a university.

- Those who wanted to participate in the study visited the school health center.

- The purposes and the processes of the study were explained to the subjects who wanted to participate in this study.

- Subjects who wanted to participate answered the questionnaire (General and disease related characteristics).

- A medical doctor assessed the subjects to determine who was fit to take the skin prick test.

- The skin prick test was performed. 
- Participating subjects answered the rest of the questionnaire (QOL of university students with allergic rhinitis).

- The wheal and erythema were measured and evaluated 15 minutes after the skin prick test.

\section{Data analysis}

The collected data were analyzed using SAS 9.3 version in terms of frequency, percentage and mean and order for the symptom type and QOL among university students with allergic rhinitis. An independent $\mathrm{t}$-test was conducted to determine whether there were any differences in QOL according to general and disease related characteristics.

\section{RESULTS}

\section{The symptoms and allergens of the participants}

Of the total 131 participants, $26.7 \%$ were male and $73.3 \%$ were female. The chief symptoms were nasal obstruction and rhinorrhea and symptoms mainly occurred in the spring season (March, April, May) and the fall season (September, October). The chief method by which the symptoms were managed was simple endurance and temperature change was reported as the primary factor for the occurrence of symptoms. The mostly widely occurring antigen is D. Farinae (Positive rate 53.4\%) and D. Pteronyssinus (48.1\%) is also prevalent. These were followed by dog hair (13.0\%), Cat hair (5.3\%), Mugwort (10.0\%), Birch-Alder (3.1\%) and Ragweed (1.5\%) (Table 1).

\section{QOL of the participants}

The mean score of QOL of the participants was 2.24 (5 point scale), which can be reconfigured as $44.7 \%$. Nasal symptoms had the highest score and affected QOL badly. Rhinorrhea $(\mathrm{M}=3.16)$ and nasal obstruction $(M=3.12)$ among the nasal symptom had the highest score in the item analysis. Generalized symptoms then followed. Fatigue $(\mathrm{M}=2.61)$ and poor concentration $(\mathrm{M}=2.51)$ had the highest score among general symptoms. This means that general symptoms which occur due to allergic rhinitis can negatively impact QOL. And then, practical problems and sleep disturbances followed respectively. Emotional problems and activity limitation were relatively minor symptoms (Table 2).

\section{QOL according to general and disease related characteristics}

QOL of the participants differed according to history of allergy diag-
Table 1. The Symptoms and Type of Allergens among the Participants $(\mathrm{N}=131)$

\begin{tabular}{|c|c|c|}
\hline Variables & Classification & Frequency (\%) \\
\hline \multirow[t]{5}{*}{ Symptom* } & Nasal obstruction & $77(58.7)$ \\
\hline & Rhinorrhea & $76(58.0)$ \\
\hline & Sneezing & $67(51.1)$ \\
\hline & Nasal itching & $48(36.6)$ \\
\hline & Eye itching \& tears & $32(24.4)$ \\
\hline \multirow[t]{12}{*}{ Occurrence* (mon) } & April & $80(61.1)$ \\
\hline & March & $68(51.9)$ \\
\hline & May & $63(48.1)$ \\
\hline & October & $54(41.2)$ \\
\hline & September & $49(37.4)$ \\
\hline & December & $47(35.9)$ \\
\hline & November & $46(35.1)$ \\
\hline & January & $43(32.8)$ \\
\hline & February & $43(32.8)$ \\
\hline & June & $42(32.1)$ \\
\hline & August & $29(22.1)$ \\
\hline & July & $27(20.6)$ \\
\hline \multirow[t]{7}{*}{ Perceived reason for the occurrence ${ }^{*}$} & Temperature change & $95(72.5)$ \\
\hline & Dust, yellow sand & $66(50.4)$ \\
\hline & Pollen & $43(32.8)$ \\
\hline & Stress & $25(19.1)$ \\
\hline & Sleep deprivation & $15(11.5)$ \\
\hline & Food & $9(6.9)$ \\
\hline & Etc. & $11(8.4)$ \\
\hline \multirow[t]{6}{*}{ Management method* } & Enduring & $90(68.7)$ \\
\hline & Medication therapy & $53(40.5)$ \\
\hline & Herbal therapy & $7(5.3)$ \\
\hline & Avoidance therapy & $4(3.1)$ \\
\hline & Folk remedy & $3(2.3)$ \\
\hline & Immune therapy & $0(0.0)$ \\
\hline \multirow[t]{8}{*}{ Allergen* } & D. farine & $70(53.4)$ \\
\hline & D. pteronyssinus & $63(48.1)$ \\
\hline & Dog hair & $17(13.0)$ \\
\hline & Mugwort & $13(10.0)$ \\
\hline & Cat hair & $7(5.3)$ \\
\hline & Birch-Alder mix & $4(3.1)$ \\
\hline & Ragweed & $2(1.5)$ \\
\hline & Aspergillus fumigatus & $0(0.0)$ \\
\hline
\end{tabular}

*Multiple choice.

nosis $(\mathrm{t}=6.10, p<.001)$. QOL also significantly differed according to the presence of rhinorrhea $(\mathrm{t}=-2.18, p=.031)$, nasal obstruction $(\mathrm{t}=-2.35, p=$ $.0 .21)$, nasal itching $(\mathrm{t}=-2.42, p=.017)$ and eye itching $(\mathrm{t}=-3.24, p=.002)$ among the main symptoms. In the season or month, QOL was lower when the symptoms occurred in March $(\mathrm{t}=-2.40, p=.018)$ and October $(\mathrm{t}=-2.62, p=.032)$. There was a difference in QOL according to the presence of pollen $(\mathrm{t}=-2.16, p=.033)$ and sleep deprivation $(\mathrm{t}=-3.35, p=.001)$ among the perceived causes of symptom occurrence. QOL of the participants differed according to allergen reaction $(\mathrm{t}=-4.44, p<.001)$. There were differences in QOL according to positive reaction to D. Farinae $(\mathrm{t}=$ 
Table 2. Quality of Life of the Participants

\begin{tabular}{|c|c|c|c|c|}
\hline Category & Item & $M(S D)$ & $\begin{array}{l}\text { Item } \\
\text { order }\end{array}$ & $\begin{array}{c}\text { Category } \\
\text { order }\end{array}$ \\
\hline \multirow[t]{4}{*}{ Practical problems } & $\begin{array}{l}\text { Need to carry a } \\
\text { handkerchief }\end{array}$ & $2.13(1.20)$ & 17 & \\
\hline & Need to rub to the nose & $2.45(1.28)$ & 9 & \\
\hline & $\begin{array}{l}\text { Need to blow the nose } \\
\text { repeatedly }\end{array}$ & $2.33(1.33)$ & 11 & \\
\hline & Sub-total & $2.30(1.13)$ & & 3 \\
\hline \multirow[t]{4}{*}{ Sleep disturbances } & Lack of good night's sleep & $2.28(1.19)$ & 13 & \\
\hline & Difficulty getting to sleep & $2.12(1.16)$ & 18 & \\
\hline & Waking up during night & $2.05(1.15)$ & 20 & \\
\hline & Sub-total & $2.15(1.08)$ & & 4 \\
\hline \multirow[t]{5}{*}{ Nasal symptoms } & Nasal obstruction & $3.12(1.32)$ & 2 & \\
\hline & Rhinorrhea & $3.16(1.33)$ & 1 & \\
\hline & Sneezing & $3.06(1.32)$ & 3 & \\
\hline & Pruritus of palate & $2.98(1.38)$ & 4 & \\
\hline & Sub-total & $3.08(1.14)$ & & 1 \\
\hline \multirow{7}{*}{$\begin{array}{l}\text { Generalized } \\
\text { symptoms }\end{array}$} & Fatigue & $2.61(1.30)$ & 5 & \\
\hline & Thirst & $2.28(1.17)$ & 14 & \\
\hline & Reduced productivity & $2.30(1.32)$ & 12 & \\
\hline & Irritability & $2.05(1.21)$ & 19 & \\
\hline & Poor concentration & $2.51(1.36)$ & 6 & \\
\hline & Headache & $2.25(1.19)$ & 15 & \\
\hline & Sub-total & $2.33(1.09)$ & & 2 \\
\hline \multirow[t]{5}{*}{ Activity limitations } & Outside activity & $1.75(1.07)$ & 23 & \\
\hline & Social activity & $1.60(0.90)$ & 28 & \\
\hline & Heavy daily activity & $1.72(1.03)$ & 24 & \\
\hline & Light daily activity & $1.66(1.01)$ & 25 & \\
\hline & Sub-total & $1.68(0.90)$ & & 7 \\
\hline \multirow[t]{5}{*}{ Emotional problems } & Frustration & $1.60(0.96)$ & 27 & \\
\hline & Anxiety & $1.60(0.95)$ & 26 & \\
\hline & Anger & $2.43(1.37)$ & 10 & \\
\hline & Embarrassment & $2.49(1.34)$ & 8 & \\
\hline & Sub-total & $2.03(0.97)$ & & 6 \\
\hline \multirow[t]{5}{*}{ Ocular symptoms } & Eye itching & $2.50(1.44)$ & 7 & \\
\hline & Sore eyes & $1.95(1.20)$ & 21 & \\
\hline & Epiphora & $2.17(1.29)$ & 16 & \\
\hline & Swollen eyes & $1.87(1.15)$ & 22 & \\
\hline & Sub-total & $2.12(1.10)$ & & 5 \\
\hline
\end{tabular}

$-4.32, p=.000)$, D. Pteronyssinus $(\mathrm{t}=-4.03, p=.000)$, Dog hair $(\mathrm{t}=-1.80$, $p=.076)$, Cat hair $(\mathrm{t}=-2.73, p=.007)$ among the allergens (Table3).

\section{DISCUSSION}

The key to diagnosis of allergic rhinitis is awareness of signs and symptoms (Skoner, 2001). The main symptoms of allergic rhinitis were nasal obstruction and rhinorrhea in our research finding and this concurred with the study carried out by Szilasi et al. (2012). This result suggests management of nasal obstruction and rhinorrhea for the patients with allergic rhinitis is essential.
The main season in which allergic symptoms most frequently occurred was spring (March, April, May) and fall (September, October) in our study. This suggests that allergic rhinitis occurs more on a seasonal basis among university students. Seasonal allergic rhinitis accounted for $52 \%$ of the incidences of allergic rhinitis in one study (Szilasi et al., 2012). Seasonal allergy might become more perennial in the future. Allergic rhinitis was identified as a main risk factor for asthma onset (Ciprandi \& Passalacqua, 2008) and early intervention is required to prevent this outcome.

Temperature change was reported as the first perceived reason for the occurrence of allergic symptoms, and this indicates that temperature management especially during seasonal changes is important as the above result findings show that allergic symptoms are reported most frequently in spring and fall. Endurance was reported as the method of allergy management in our study, and this means that many students simply endured despite suffering from severe symptoms; accordingly, they need to be educated or counseled with regarding their symptom management methods. Also, There is need to identify the reason why they have chosen simply to endure. The next most popular method of management was the use of medication in our research finding. However, it has been recorded in one study that medication is only helpful in relieving the symptoms temporarily, not at dealing with the root cause and allergen avoidance is more highly recommended (Hayden \& Womack, 2007).

The main allergen was house dust mite in our study. Positive reaction to house dust mite was over $50 \%$ in our participants but previous research findings reported that 24.3\% (Kong, 2009) 32.9\% (Aburuz, Bulatova, \& Tawalbeh, 2011) had a positive reaction. So, we can postulate that the number of people who are becoming sensitive to house dust mite is increasing gradually.

The QOL score among the participants in our study was 2.24 (5 point), or about $44.7 \%$, and is similar to a previous study that included female college students in which the QOL was reported as 44.9\% (Kim, 2009). Managing patients with allergic rhinitis can be a very satisfying part of nursing practice, as it often makes a significant difference to an individual's QOL (Tickle \& Sewell, 2007). The worst factor affecting QOL was nasal symptoms and the recorded figure was about $61.4 \%$, indicating that many participants suffer because of nasal symptoms. Previous research also reported that over $85 \%$ of young adult patients were affected by rhinorrhea, nasal obstruction, nasal itchiness, and sneezing (Demoly et al., 2002). So, when a program for university students with allergic rhinitis is developed, methods of prevention and management 
Table 3. Differences in Quality of Life according to General and Disease Related Characteristics

\begin{tabular}{|c|c|c|c|c|c|c|}
\hline \multirow{2}{*}{ Variables } & \multirow{2}{*}{ Category } & & \multirow{2}{*}{ n (\%) } & \multicolumn{3}{|c|}{$\mathrm{QOL}$} \\
\hline & & & & $M(S D)$ & $\mathrm{t}$ & $p$ \\
\hline \multirow[t]{2}{*}{ Gender } & \multirow{2}{*}{\multicolumn{2}{|c|}{$\begin{array}{l}\text { Male } \\
\text { Female }\end{array}$}} & $35(26.7)$ & $2.46(0.88)$ & 1.70 & .092 \\
\hline & & & $96(73.3)$ & $2.17(0.88)$ & & \\
\hline \multirow[t]{2}{*}{ Family history } & \multicolumn{2}{|l|}{ Yes } & $69(58.0)$ & $2.28(0.89)$ & 1.30 & .197 \\
\hline & \multicolumn{2}{|l|}{ No } & $50(42.0)$ & $2.07(0.83)$ & & \\
\hline \multirow[t]{2}{*}{ Diagnosis history } & \multicolumn{2}{|l|}{ Yes } & $71(54.2)$ & $2.63(0.83)$ & 6.10 & $<.001$ \\
\hline & \multicolumn{2}{|l|}{ No } & $60(45.8)$ & $1.80(0.72)$ & & \\
\hline \multirow{5}{*}{ Housing type } & \multicolumn{2}{|l|}{ House } & $26(19.9)$ & $3.58(0.95)$ & 2.05 & .091 \\
\hline & \multicolumn{2}{|l|}{ Dormitory } & $33(25.2)$ & $4.08(0.83)$ & & \\
\hline & \multicolumn{2}{|l|}{ One room } & $30(22.9)$ & $3.60(0.94)$ & & \\
\hline & Apartment & & $40(30.5)$ & $3.80(0.78)$ & & \\
\hline & Etc & & $2(1.53)$ & $3.00(0.51)$ & & \\
\hline Symptom* & Sneezing & Yes & $67(51.2)$ & $2.26(0.94)$ & -0.21 & .832 \\
\hline & & No & $64(48.9)$ & $2.23(0.83)$ & & \\
\hline & Rhinorrhea & Yes & $76(58.0)$ & $2.39(0.89)$ & -2.18 & .031 \\
\hline & & No & $55(42.0)$ & $2.05(0.85)$ & & \\
\hline & Nasal obstruction & Yes & $77(58.8)$ & $2.40(0.90)$ & -2.35 & .021 \\
\hline & & No & $54(41.2)$ & $2.04(0.83)$ & & \\
\hline & Nasal itching & Yes & 48 (36.6) & $2.49(0.87)$ & -2.42 & .017 \\
\hline & & No & $83(63.4)$ & $2.11(0.87)$ & & \\
\hline & Eye itching \& tears & Yes & $32(24.4)$ & $2.67(0.95)$ & -3.24 & .002 \\
\hline & & No & $99(75.6)$ & $2.11(0.82)$ & & \\
\hline Occurrence* (mon) & March & Yes & $68(51.9)$ & $2.42(0.86)$ & -2.39 & .018 \\
\hline & & No & $63(48.1)$ & $2.06(0.88)$ & & \\
\hline & April & Yes & $80(61.1)$ & $2.33(0.84)$ & -1.27 & .208 \\
\hline & & No & $51(38.9)$ & $2.13(0.95)$ & & \\
\hline & May & Yes & $63(48.1)$ & $2.39(0.85)$ & -1.73 & .086 \\
\hline & & No & $68(51.9)$ & $2.12(0.91)$ & & \\
\hline & October & Yes & $54(40.9)$ & $2.45(0.91)$ & -2.61 & .032 \\
\hline & & No & $77(58.8)$ & $2.11(0.85)$ & & \\
\hline Perceived reason for the occurrence ${ }^{*}$ & Temperature change & Yes & $95(77.2)$ & $2.32(0.90)$ & -1.11 & .270 \\
\hline & & No & $28(22.8)$ & $2.11(0.85)$ & & \\
\hline & Pollen & Yes & $43(35.0)$ & $2.51(0.93)$ & -2.16 & .033 \\
\hline & & No & $80(65.0)$ & $2.15(0.84)$ & & \\
\hline & Dust, yellow sand & Yes & $66(53.7)$ & $2.38(0.91)$ & -1.46 & .148 \\
\hline & & No & $57(46.3)$ & $2.15(0.85)$ & & \\
\hline & Stress & Yes & $25(20.3)$ & $2.56(0.93)$ & -1.86 & .066 \\
\hline & & No & $98(79.7)$ & $2.20(0.87)$ & & \\
\hline & Sleep deprivation & Yes & $15(12.2)$ & $2.96(0.91)$ & -3.35 & .001 \\
\hline & & No & $108(87.8)$ & $2.18(0.85)$ & & \\
\hline & Food & Yes & $9(7.3)$ & $2.61(0.87)$ & -1.19 & .240 \\
\hline & & No & $114(92.7)$ & $2.25(0.88)$ & & \\
\hline Skin Prick test & Positive & & $76(58.0)$ & $2.52(0.81)$ & -4.44 & $<.001$ \\
\hline & Negative & & $55(42.0)$ & $1.87(0.85)$ & & \\
\hline Allergen & D. farinae & Positive & $70(53.4)$ & $2.54(0.81)$ & -4.32 & .000 \\
\hline & & Negative & $61(46.6)$ & $1.91(0.85)$ & & \\
\hline & D. pteronyssinus & Positive & $63(48.1)$ & $2.55(0.86)$ & -4.03 & .000 \\
\hline & & Negative & $68(51.9)$ & $1.97(0.83)$ & & \\
\hline & Cat hair & Positive & $7(5.3)$ & $3.12(0.75)$ & -2.74 & .007 \\
\hline & & Negative & $124(94.7)$ & $2.20(0.87)$ & & \\
\hline & Dog hair & Positive & $17(13.0)$ & $2.60(0.76)$ & -1.79 & .076 \\
\hline & & Negative & $114(87.0)$ & $2.20(0.89)$ & & \\
\hline & Ragweed & Positive & $2(1.5)$ & $3.36(0.51)$ & -1.80 & .074 \\
\hline & & Negative & $129(98.5)$ & $2.23(0.88)$ & & \\
\hline & Mugwort & Positive & $13(9.9)$ & $2.37(0.73)$ & -0.50 & .616 \\
\hline & & Negative & 118 (90.1) & $2.24(0.90)$ & & \\
\hline & Birch-alder mix & Positive & $4(3.1)$ & $3.53(0.38)$ & -6.51 & .003 \\
\hline & & Negative & $127(97.0)$ & $2.21(0.87)$ & & \\
\hline
\end{tabular}

*Multiple choice. 
for nasal symptoms, especially nasal obstruction and rhinorrhea should be included.

Fatigue among the generalized symptoms was also a main factor for lower QOL. So, fatigue also needs to be managed. Song \& Suh (2010) reported that the use of aromatic oil can relieve the fatigue of patients with allergic rhinitis. Poor concentration also should be managed because it can negatively impact school work and productive learning. But, management of nasal symptoms is important above all because fatigue and poor concentration are closely associated with nasal symptoms (Meltzer, Gross, Katial, \& Storms, 2012).

In this study, there were differences in quality of life with some variables such as symptoms (presence or absence of rhinorrhea, nasal obstruction and nasal or eye itching), occurrence month (March and October), perceived reason (pollen and sleep deprivation), skin test (mite and cat hair and birch-alder mix positive).

Among nasal symptoms, there were differences affecting QOL according to whether such symptoms as rhinorrhea, nasal obstruction, nasal itching and eye-itching and eye watering were present or not. But no such difference affecting QOL was recorded with regard to whether the symptom of sneezing was present or not, which probably indicates that sneezing temporarily alleviates the impulse to itch and helps eliminate materials within the oral cavity and brings some comfort to the patient.

There were differences affecting QOL according to the season (March and October), and this probably is related to the rapid temperature change or increase in pollens in the spring and fall seasons. In our research findings, among the perceived causes of symptom occurrence, temperature change did not seem to affect QOL but the presence of pollens did. However, the number of participants who had a positive reaction to pollens (Ragweed, Mugwort and Birch-alder mix) was small, so further study with regard to temperature change and pollens is needed if we are to learn why QOL is related to the seasons.

Sleep deprivation also had an impact on QOL. It is thought that sleep deprivation impairs the immune system and allergic rhinitis is associated with impaired immune response. In fact, as populations around the world age, greater interest in immunologic responses during the aging process is developing and greater interest in allergic rhinitis is also beginning to develop (Ventura et al., 2012). In the future, sleep is needs to be managed for the patients with allergic rhinitis and further study with regard to immunity is also needed.

Additionally, the participants who had a positive reaction to the skin prick test had lower QOL. There were big differences in QOL according to whether house dust mite sensitivity was present or not. As positive allergy skin tests are significant risk factors for development of new symptoms (Skoner, 2001) and the occurrence of allergic symptoms may be more serious when one has a positive reaction to some allergen, allergens should be detected and treated. Allergen avoidance is essential (Hayden \& Womack, 2007), so a program for university students with allergic rhinitis needs to include methods for treating and avoiding house dust mites as a major allergen that produces allergic reactions.

\section{CONCLUSION}

As the number of people suffering from allergic rhinitis brought on by environmental influences increases, the necessity of implementing nursing strategies for people with allergic rhinitis has also increased. This research was aimed at providing data which would be helpful in developing a program for students with allergic rhinitis. Nasal obstruction and rhinorrhea occurred most frequently among the nasal symptoms and the most popular allergens were dust ticks and the seasons in which allergic symptoms most commonly occurred were spring and fall. QOL differed according to nasal obstruction and rhinorrhea and dust ticks and the season. A program initiated in the spring and fall that includes management methods for nasal symptom such as nasal obstruction and rhinorrhea and preventing or managing house dust mites could increase the allergic rhinitis related QOL of university students. Developing a program for university students that focuses on allergic rhinitis has significance for our society because the incidence of allergic rhinitis among this group has increased and the health status of people in their twenties is important for the economic productivity of our society. Further study to develop a management program for university students with allergic rhinitis and to test its' effects is recommended.

\section{REFERENCES}

Aburuz, S., Bulatova, N., \& Tawalbeh, M. (2011). Skin prick test reactivity to aeroallergens in Jordanian allergic rhinitis patients. Eastern Mediterranean Health Journal, 17, 604-610.

Baiardini, I., Braido, F., Tarantini, F., Porcu, A., Bonini, S., Bousquet, P. J., et al. (2008). ARIA-suggested drugs for allergic rhinitis: What impact on quality of life? A GA2LEN review. Allergy, 63, 660-669.

Brozek, J. L., Bousquet, J., Baena-Cagnani, C. E., Bonini, S., Canonica, G. W., Casale, T. B., et al. (2010). Allergic rhinitis and its impact on asthma (ARIA) guidelines: 
2010 Revision. Journal of Allergy and Clinical Immunology, 126, 466-476. http:// dx.doi.org/10.1016/j.jaci.2010.06.047

Ciprandi, G., \& Passalacqua, G. (2008). Allergy and the nose. Clinical and Experimental Immunology, 153(Suppl.1), 22-26. http://dx.doi.org/10.1111/j.13652249.2008.03717.x

Dalal, A. A., Stanford, R., Henry, H., \& Borah, B. (2008). Economic burden of rhinitis in managed care: A retrospective claims data analysis. Annals of Allergy, Asthma \& Immunology, 101, 23-29. http://dx.doi.org/10.1016/S1081-1206(10) 60830-7

Demoly, P., Allaert, F. A., \& Lecasble, M. (2001). ERASM, a pharmacoepidemiologic survey on management of intermittent allergic rhinitis in every day general medical practice in France. Allergy, 57, 546-554.

Demoly, P., Jankowski, R., Chassany, O., Bessah, Y., \& Allaert, F. A. (2011). Validation of a self-questionnaire for assessing the control of allergic rhinitis. Clinical e Experimental Allergy, 41, 860-868. http://dx.doi.org/10.1111/j.1365-2222.2011. 03734.x

Faul, F., Erdfelder, E., Buchner, A., \& Lang, A. G. (2009). Statistical power analyses using $G^{\star}$ Power 3.1: Tests for correlation and regression analyses. Behavior Research Methods, 41, 1149-1160.

Greiner, A. N., Hellings, P. W., Rotiroti, G., \& Scadding, G, K. (2011). Allergic rhinitis, Lancet, 378, 2112-2122. http://dx.doi.org/10.1016/S0140-6736(11)60130-X

Hayden, M. L., \& Womack, C. R. (2007). Caring for patients with allergic rhinitis. Journal of American Academy of Nurse Practitioners, 19, 290-298.

Holmes, S., \& Scullion, J. (2012). Allergic rhinitis: Assessment and treatment. Nurse Prescribing, 10, 222-228.

Jegatheesan, V., \& Shu, L. (2009). Special issue on the challenges in environmental science and engineering, CESE-2009 14-17 July, 2009-Jupiters hotel, Townsville, Queensland, Australia. Desalination \& Water Treatment, 11, 1-3. http://dx.doi. org/10.5004/dwt.2009.834

Kim, A. Y. (2009). The Effects of mindfulness meditation on attention and quality of life in allergic rhinitis for female college students. Unpublished master's thesis. Ducksung Women's University, Seoul, Korea.

Kong, S. K. (2009). Epidemiological characteristics of allergy rhinitis patients called at a medical practitioner's office for otorhinolaryngology. Unpublished master's thesis. Chungnam National University, Daejeon, Korea.

Meltzer, E. O., Gross, G. N., Katial, R., \& Storms, W. W. (2012). Allergic rhinitis substantially impacts patient quality of life: Findings from the nasal allergy survey assessing limitations. Journal of Family Practice, 6(Suppl. 2), S5-S10.

Ministry of Environment. (2008). The first survey on environmental health awareness of Korean people. The Press Release of Ministry of Environment, 2008. Retrieved February 15, 2012, from http://www.kdi.re.kr/infor/ep_view.jsp?num=98824
Ministry of Health and Welfare. (2009). 2008 National health statistics-The 4th National Health and Nutritional Survey. Publication No, 11-1351159-000027-10. Retrieved February 10, 2012, from http://knhanes.cdc.go.kr/knhanes/index.do

O'Connor, J., Seeto, C., Saini, B., Bosnic-Anticevich, S., Krass, I., Armour, C., et al. (2008). Healthcare professional versus patient goal setting in intermittent allergic rhinitis. Patient Education and Counseling, 70, 111-117. http://dx.doi.org/10.1016/ j.pec.2007.09.004

Park, K. H., Cho, J. S., Lee, K. H., Shin, S. Y., Moon, J. H., \& Cha, C. I. (2002). Rhinoconjunctivitis quality of life questionnaire (RQLQ) as an evaluator of perennial allergic rhinitis patients -The first report-. Korean Journal of OtolaryngologyHead and Neck Surgery, 45, 254-262.

Schatz, M., Meltzer, E. O., Nathan, R., Derebery, M. J., Mintz, M., Stanford, R. H., et al., (2010). Psychometric validation of the rhinitis control assessment test: A brief patient-completed instrument for evaluating rhinitis symptom control. Annals of Allergy, Asthma \& Immunology, 104, 118-124.

Skoner, D. P. (2001). Allergic rhinitis: Definition, epidemiology, pathophysiology, detection, and diagnosis. Journal of allergy and clinical immunology, 108(1 Supple), S2-S8. http://dx.doi.org/10.1067/mai.2001.115569

Son, K. Y., Park, K. S., Hwang, H. H., Yun, B. S., Lee, S. J., Kim, M. A., et al. (2007). Prevalence of allergic diseases among primary school children in Ilsan, Gyeonggi and changes of symptoms after environmental control in 2005. Pediatric Allergy and Respiratory Disease, 17, 384-393.

Song, M. S., \& Suh, Y. S. (2010). Effects of aromatherapy on blood pressure, pulse, fatigue, and sleep for patients with allergic rhinitis. Journal of Korean Society of Biological Nursing Science, 12, 16-23.

Szilasi, M., Galffy, G., Fonay, K., Mark, Z., Ronai, Z., Szalai, Z., et al. (2012). A survey of the burden of allergic rhinitis in Hungary from a specialist's perspective. Multidisciplinary Respiratory Medicine, 7, 49. http://dx.doi.org/10.1186/2049-6958-7-49

The American College Health Association. (2008). American college health association-national college health assessment spring 2007 reference group data report (Abridged). Journal of American College Health, 56, 469-479.

Thompson, A. K., Juniper, E., \& Meltzer, E. O. (2000). Quality of life in patients with allergic rhinitis. Annals of Allergy, Asthma \& Immunology, 85, 338-347.

Tickle, J., \& Sewell, C. (2007). Managing allergic rhinitis. Practice Nurse, 33(8), 15-19. Ventura, M. T., Gelardi, M., D’Amato, A., Buquicchio, R., Tummolo, R., Misciagna, G., et al. (2012). Clinical and cytologic characteristics of allergic rhinitis in elderly patients. Annals of Allergy, Asthma and Immunology, 108(3), 141-144. http://dx. doi.org/10.1016/j.anai.2012.01.013

World Health Organization. (2002, January). Prevention of allergy and allergic asthma. Retrieved March 4, 2011, from http://www.worldallergy. org/professional/ who_paa2003.pdf/ 